\title{
Implementação e reformulação de políticas públicas: o caso do programa Cultura Viva
}

\author{
Anny Karine de Medeiros \\ Fundação Getúlio Vargas (FGV/SP)
}

Marta Ferreira Santos Farah

Fundação Getúlio Vargas (FGV/SP)

\section{Implementação e reformulação de políticas públicas: o caso do programa Cultura Viva}

O presente artigo tem por objetivo demonstrar como um processo de implementação se modifica e é adaptado ao longo do tempo, podendo conduzir a um redesenho da política pública. Utiliza-se como estudo de caso o programa Cultura Viva. A pesquisa em que se baseia o artigo foi realizada por meio de entrevistas semiestruturadas com gestores do programa Cultura Viva e gestores de pontos de cultura, bem como por meio de um survey com os pontos de cultura do Estado de São Paulo e seus Municípios. Os resultados revelam que a implementação do programa alterou os critérios estabelecidos no processo de formulação e incluiu novos instrumentos de gestão, redesenhando assim a política pública.

Palavras-chave: políticas públicas, política cultural, estudo de caso, implementação, accountability

\section{Implementación y replanteamiento de políticas públicas: el caso del programa Cultura Viva}

Este artículo tiene el objetivo de demostrar como un proceso de implementación se modifica y es adaptado con el tiempo, lo que conduce a un rediseño de las políticas públicas. Se utiliza como estudio de caso el programa Cultura Viva. La investigación en que se apoya este artículo fue realizada utilizando entrevistas semi-estructuradas con los directores y gestores del programa Cultura Viva y gestores de puntos de cultura, así como un survey de los puntos de la cultura del Estado de São Paulo y sus municipios. Los resultados obtenidos muestran que el proceso de implementación del programa ha cambiado los criterios

Artigo recebido em novembro de 2013. Versão final em março de 2014. 
definidos en el proceso de formulación, e ha incluido nuevas herramientas de gestión, lo que constituye el rediseño de las políticas públicas.

Palabras clave: política pública, política cultural, estudio de caso, implementación, accountability

\section{Implementing and redesigning public policy: the case of Cultura Viva program}

This article aims to demonstrate how an implementation process is modified and adapted over time, leading to a redesign of public policy. The case study of the Cultura Viva program is used to reach this goal. The research on which the article is based was conducted through semi-structured interviews with managers and organizations that became part of Cultura Viva program, as well as a survey carried in cultural spots from the state of São Paulo and its municipalities. Results show that the implementation process of the program changed the criteria defined on the formulation process and included new management tools, thereby redesigning public policy.

Keywords: public policy, cultural policy, case study, implementation, accountability

\section{Introdução}

O objetivo do presente artigo é demonstrar como um processo de implementação é modificado e adaptado ao longo do tempo. Utiliza-se como estudo de caso o programa Cultura Viva, que consiste no apoio descentralizado a atividades culturais até então excluídas do mercado e do apoio estatal, por meio de convênios para transferência de recursos para organizações culturais selecionadas em edital. Analisa-se o programa Cultura Viva a partir de sua implementação em âmbito federal, por meio da Portaria Interministerial no 156 de 2004, e detalha-se o processo de descentralização até o seu redesenho, em 2013, data de conclusão da pesquisa.

O programa Cultura Viva parte de uma ideia simples: incentivar ações (culturais) que já existem no cotidiano de comunidades e grupos culturais, propiciando sua continuidade e sua institucionalização como "pontos de cultura". Organizações culturais se candidatam a editais do programa, por meio de um plano de trabalho por elas desenvolvido, contendo as ações que serão realizadas pela organização após sua aprovação. Quando aprovadas, as organizações tornam-se pontos de cultura, obtendo apoio governamental para suas atividades, ou tornam-se pontões de cultura, cuja principal função é articular os demais pontos de cultura para formar uma rede de ações, ou rede de pontos de cultura. Esses instrumentos de gestão apoio direto às comunidades e constituição de redes, mesmo que simples, empoderam comunidades e grupos culturais. Embora essas comunidades e grupos culturais precisem firmar convênios para receber os recursos e devam se estruturar por meio de redes, os instrumentos de gestão não estabelecem o que será incentivado. A ação cultural a ser apoiada é, em geral, a que já é desenvolvida pelo 
grupo que recebe o apoio, incluindo desde manifestações como o maracatu, o mamulengo e a contação de histórias até o canto lírico, ou outra linguagem artística, seja essa considerada tradicional ou não.

Após a entrada na agenda governamental do tema "inclusão de segmentos excluídos", na política pública da cultura, e após a formulação do programa Cultura Viva - processos apresentados de forma sintética no presente artigo -, a implementação do novo programa se dá a partir da promulgação dos editais e do estabelecimento de convênios com organizações culturais que, uma vez conveniadas, tornam-se pontos de cultura e passam a desenvolver seus planos de trabalho. O trabalho discute esse processo de implementação, com ênfase na análise da adaptação de mecanismos estabelecidos na etapa de formulação. Questiona-se como a ação das organizações culturais redefine a implementação da política cultural, no caso, o programa Cultura Viva.

O artigo é resultado de pesquisa exploratória, partindo de revisão bibliográfica sobre a literatura especializada para embasar um survey que visou a abranger o universo de pontos e pontões de cultura. Um questionário estruturado com 20 perguntas abertas e fechadas foi enviado para os pontos de cultura do Estado de São Paulo e seus Municípios. Trinta e um gestores de pontos de cultura responderam voluntariamente ao questionário, enviado por meio de mala direta eletrônica para o universo de pontos e pontões de cultura do Estado de São Paulo ${ }^{1}$. Complementando a pesquisa exploratória, uma pesquisa de campo foi realizada por meio de entrevistas semiestruturadas com gestores do programa Cultura Viva (dois) e gestores de pontos de cultura (cinco) selecionados entre os respondentes do survey.

A análise tem por foco a etapa de implementação do programa Cultura Viva, uma vez que é nessa etapa que as políticas e programas se concretizam, evidenciando gargalos e potencialidades, cujo reconhecimento pode subsidiar a reformulação da política. Mais do que isso, como o artigo procura demonstrar, ao longo da implementação, o programa vai sendo reformulado no processo.

\section{Agenda e formulação do programa Cultura Viva}

O programa Cultura Viva tem suas raízes na busca por apoio a projetos culturais de forma descentralizada, bandeira essa defendida por representantes da

\footnotetext{
${ }^{1}$ Universo integrado pelos pontos de cultura e pontões selecionados e aprovados por editais do Governo Federal, do governo estadual ou de municípios, lançados até dezembro de 2012.
} 
sociedade civil, em especial grupos culturais excluídos das formas tradicionais de financiamento à área da cultura. A proposta de dinamização da cultura local já estava presente no cenário brasileiro há décadas, sendo um dos elementos centrais das demandas de movimentos sociais dessa área (CALABRE, 2009). Essa proposta ganhou força no contexto da redemocratização, especialmente após a Constituição Federal de 1988, dado que pressupõe a mobilização de atores societários e concebe a cultura como direito.

A identificação da potência da cultura local levou Célio Turino (formulador do programa) a desenvolver um programa baseado em pontos de cultura, pela primeira vez, quando Secretário de Cultura do Município de Campinas (SP). A experiência de Campinas, mesmo não tendo continuidade, enquanto política cultural, com a troca de gestão, destacou que a articulação em rede com outras organizações, a existência de vínculos comunitários e o protagonismo dos envolvidos foram elementos que favoreceram a continuidade, mesmo sem apoio da nova gestão, da (única) experiência bem-sucedida de ponto de cultura à época.

Anos após a experiência de Campinas, o Ministério da Cultura (MinC) passou a valorizar processos existentes, por meio do incentivo a grupos culturais deslocados do "mercado", de forma que esses pudessem desenvolver suas ações na comunidade do entorno. Entende-se por grupos culturais "deslocados do mercado" aqueles que não possuem aporte administrativo suficiente para submeter projetos a linhas de financiamento que exigem muitos procedimentos técnicos, e que não têm acesso a financiamento público, bem como grupos que trabalham linguagens artísticas negligenciadas e marginalizadas. O programa Cultura Viva parte, então, dos conceitos de protagonismo e articulação em rede (MINc, 2010; TURINo, 2009), ao permitir que as próprias comunidades desenvolvam e apresentem a sua cultura nas palavras de Célio Turino: "não dizendo o que as comunidades querem [fazer], mas perguntando como o querem" (TuRINo, 2009, p. 63).

Ainda que haja o reconhecimento da "exclusão do acesso à produção cultural" como um problema público e que existam soluções plausíveis para seu enfrentamento, a elevação dessa questão à agenda governamental depende da dinâmica política na qual está inserida(KINGDoN, 2003; FreY, 2000). O campo das políticas públicas é permeado por diversos interesses, muitas vezes conflitantes, e a disputa entre diferentes posições políticas influencia tanto a definição do problema (BARDACH, 2009; FuKs, 2000), como a tomada de decisão em relação à alternativa de ação e à política a ser adotada (FuKs, 2000; SUBIRATS, 2012). Dificilmente serão direcionados esforços para a solução do problema identificado se não houver interesse político e atores dispostos a enfrentar tal problema. Para que o problema seja identificado e reconhecido como algo a ser tratado pelo poder público, contribuem fatores como a influência política de grupos de pressão e as mudanças 
político-administrativas, já que a troca de gestão permite uma abertura para "novos" problemas (KINGDON, 2003).

O programa Cultura Viva surgiu em 2004, ano de mudanças no cenário político federal, momento em que o Partido dos Trabalhadores (PT) assumiu a Presidência da República e Gilberto Gil, o MinC. Segundo Kingdon (2003), a formação da agenda de políticas públicas é o resultado da junção de três fluxos, sendo eles o de problemas, o de soluções e o da dinâmica política, em uma janela de oportunidade que permita a confluência desses fluxos. A mudança de diretrizes governamentais proporcionada pela eleição do partido anteriormente em oposição ao governo - foi um fator fundamental para a abertura de uma janela de oportunidade para a formulação e a implementação de políticas com vieses distintos dos até então vigentes. Isso porque novos atores ascenderam aos papéis de formuladores de políticas públicas e interlocutores das comunidades epistêmicas, baseados em um projeto político distinto do até então vigente. É possível considerar o papel relevante exercido por uma coalizão advocatória reunindo movimentos sociais, membros do PT, segmentos da comunidade epistêmica da área da cultura e atores que atuaram como "empreendedores" no sentido proposto por Kingdon (2003). Essa coalizão contribuiu para que a exclusão de determinados grupos e "tipos" de manifestação cultural do acesso ao apoio de políticas públicas e programas governamentais passasse a ser considerada um problema e para que fossem desenhadas alternativas de ação que enfrentassem esse problema.

Além do momento político de transição governamental, a falta de recursos disponíveis para o desenvolvimento de políticas culturais favoreceu a formulação e a implementação do programa Cultura Viva. Célio Turino (2009) destacou a potencialidade de disseminação do programa, utilizando-se das estruturas das organizações culturais, tendo como contrapartida o baixo investimento por parte do governo para incentivar novas ações, e assim incrementar (e muitas vezes legitimar) o que já vinha sendo realizado. Nesse sentido, esse programa constitui uma alternativa viável, cujo processo de implementação é tema do presente artigo.

\section{Implementação do programa}

A implementação de políticas públicas, enquanto tema de estudo, tem diversas abordagens. Winter (2010) sistematizou as chamadas teorias de implementação em três gerações: (1) estudos de caso focados em problemas para criação de uma "teoria geral" (década de 1970); (2) construção de modelos teóricos ou estruturas 
de análise, como os modelos "de cima para baixo" e "de baixo para cima" (década de 1980); e (3) estudos focados em casos isolados para entender as variáveis envolvidas e as particularidades dos processos de implementação, abordagem de que se aproxima o presente artigo.

Entre os modelos teóricos que marcam a terceira geração de estudos apontados acima, há abordagens segundo as quais as idealizações realizadas durante o processo de formulação podem ser alteradas durante o processo de implementação. Nesse sentido, baseiam-se na visão da implementação enquanto um “jogo" (BARDACH, 1977), um campo de incertezas no qual implementadores precisam adaptar constantemente aquilo que foi previamente formulado. Isso porque a implementação, enquanto etapa, guarda também fatores de "adaptação": decisões são tomadas, imprevistos ocorrem, e, sobretudo, há discricionariedade dos agentes responsáveis pela implementação, influenciando as ações realizadas (BARDACH, 1977). Os autores dessa terceira geração também adotam uma concepção do processo de implementação que reconhece o convívio de elementos da abordagem "de cima para baixo" com elementos da perspectiva "de baixo para cima" (MAJOne e WiLdawsy, 1995, WinTeR, 2003, HiLL, 2006, Silva e Melo, 2000). Isso significa reconhecer que a formulação e o plano inicial têm certa eficácia, mas que a implementação redefine o plano ao longo de todo o processo e, portanto, a própria política ou programa (FARAH, no prelo). O presente artigo se aproxima das perspectivas propostas por esses autores.

O programa Cultura Viva começou a ser implementado ainda no ano de 2004. A implementação, enquanto ação governamental, ocorre a partir do momento em que são lançados os editais para seleção de pontos de cultura, e esses são selecionados. Após a seleção dos pontos de cultura e repasse das parcelas do recurso, os projetos passam a ser executados pelas organizações culturais, cabendo ao órgão governamental (ministério ou secretaria) o acompanhamento dos projetos.

Cabe destacar, neste ponto, a tendência das políticas brasileiras em realizar parcerias com organizações não governamentais de caráter social e cultural para a implementação de políticas públicas. Apesar de não ser o foco do presente artigo, aponta-se o papel dessas organizações não governamentais na implementação de políticas, conforme detalhado posteriormente.

Ao longo da implementação do programa, foram feitas alterações e adaptações, algumas novas ações foram sendo criadas, enquanto outras ações concebidas inicialmente - foram extintas. A fim de ilustrar essas mudanças, a implementação do programa foi dividida em três fases que, acredita-se, demonstram as principais alterações e adaptações ocorridas, além de destacar 
o papel das organizações no processo de implementação. Vale destacar que a divisão apresentada não é estanque, dado que as fases se intercalam e se justapõem.

\section{Primeira fase do programa}

A aceitação do modelo do programa Cultura Viva foi o ponto de partida para o processo de implementação, que se iniciou em 2004, por meio da Portaria Ministerial no 156/2004. A partir dessa portaria, foi lançado o primeiro edital de seleção para pontos de cultura, vinculados diretamente com o MinC, e iniciou-se o que será aqui considerada como a primeira fase de implementação, com a seleção de projetos para pontos de cultura em 2005.

A identificação e o apoio a pontos de cultura são a ação prioritária do programa Cultura Viva. Uma vez selecionadas, as organizações culturais passam a ser reconhecidas como pontos de cultura, e implementam seu plano de trabalho previamente formulado, apoiadas financeira e institucionalmente pelo MinC, por meio da Secretaria de Cidadania e da Diversidade Cultural -SCDC (MıNc, 2012). Além dos pontos de cultura, outra importante iniciativa dessa primeira fase foi o pontão de cultura, cujo objetivo é "articular os pontos de cultura de suas áreas de especialização, auxiliando na capacitação desses pontos de cultura e na difusão do conhecimento por eles produzido", estruturando as redes de pontos de cultura (MıNc, 2012).

Além dos pontos e pontões de cultura, o programa inclui os pontinhos de cultura, com foco na infância, e algumas ações complementares: Ação Cultura Digital, Ação Griô, Ação Escola Viva e Ação Agente Cultura Viva. As ações complementares correspondem àquelas que podem se somar aos pontos e pontões existentes, mas também incentivam organizações culturais que não sejam pontos de cultura. As ações complementares podem favorecer pessoas físicas e linguagens artísticas específicas, como, por exemplo, cultura digital e educação. Essas ações complementares têm grande potencial de interação e transversalidade (REINACH, 2013), já que se comunicam e se articulam para o mesmo objetivo: tornar o acesso à cultura mais disseminado. 0 programa Cultura Viva utilizou-se, ainda, do formato de prêmios para incentivar as organizações, sendo o recurso de cada prêmio repassado à organização cultural selecionada (SARTOR, 2011).

Os primeiros meses do programa Cultura Viva revelaram um crescimento exponencial de projetos conveniados (Silva e Araúso, 2010; Silva et al., 2011). Esse crescimento inicial deu visibilidade ao programa, enquanto surgiram seus primeiros impactos políticos, dado que os pontos de cultura se inserem no quadro de relações de poder nos Municípios, por meio do financiamento do Governo Federal. A dimensão política foi marcante no programa Cultura Viva, tendo ocorrido 
mobilização de secretários de Estados e Municípios para questionar a transferência de recursos, conforme narrado pelo idealizador do programa:

Em 2004, quando saiu o primeiro edital, houve uma reunião dos secretários de cultura estaduais com o Gilberto Gil para protestar. Eles afirmavam que era uma ingerência, que projetos que eles conheciam que eram muito bons, uma academia de letras que estava lá há cem anos, e não foram contemplados, enquanto outros que eles não consideravam nem que faziam cultura foram contemplados, como um quilombo, por exemplo (TURINo, entrevista concedida às autoras em 22 de janeiro de 2013).

Uma alternativa adotada para contornar os conflitos e para fortalecer e disseminar o programa Cultura Viva foi aproximar Estados e Municípios por meio da criação de editais estaduais e municipais, marcando o que será aqui considerada a segunda fase do programa.

\section{Segunda fase do programa}

A partir de 2007, Estados e Municípios realizaram convênios com o MinC, dando início às redes estaduais e municipais de pontos de cultura, também conhecidos como "pontos de rede". Considera-se essa a segunda fase do programa, marcada pela parceria de Estados e Municípios com o MinC, que passam a dividir as responsabilidades financeiras e de gestão, lançar editais e articular pontos de cultura. As relações estabelecidas entre os três níveis de governo (federal, estadual e municipal) configuram uma gestão compartilhada do programa (BARBOSA et al., 2011).

A rede de pontos de cultura então se complexificou, pois um ponto de cultura passou a poder ser vinculado exclusivamente ao MinC, ou ser vinculado a uma secretaria estadual ou municipal e ao MinC. O número de pontos de cultura se ampliou com a inserção de novos parceiros, marcando a segunda fase do programa como momento de ampliação e estruturação das novas redes. O órgão governamental "parceiro" (secretarias de cultura estaduais ou municipais) passou a executar também funções de pontão de cultura (SARTOR, 2011), e cada novo membro trouxe, além de si, seus contatos e redes próprias.

Ainda que alguns municípios, no primeiro momento, tenham se mostrado contrários ao modelo, as redes estaduais e municipais foram as responsáveis pela ampliação do programa durante sua segunda fase. Dados obtidos por meio da Lei de Acesso à Informação (SIC, 2012) apontaram a representatividade que as redes estaduais assumiram na segunda fase do programa, uma vez que 497 organizações culturais tornaram-se pontos de cultura em editais de 2004 e 2005, mas foi por meio dos editais das redes estaduais e municipais que 1.822 
organizações culturais foram selecionadas, em 2007. O número de pontos de rede estaduais mostrou-se superior à soma de todos os editais federais, apesar de o crescimento da rede de pontos de cultura não refletir o crescimento da equipe técnica que coordena o programa no MinC, restrita a poucas dezenas de pessoas responsáveis pelos milhares de pontos de cultura que se acumulam.

Segundo a pesquisa de Barbosa, Medeiros e Lyra (2011), a inclusão de outros níveis de governo disseminou as ações pelo território nacional e aproximou os gestores públicos das secretarias aos pontos de rede, ao mesmo tempo que tornou as ações mais complexas, pois o convênio com redes estaduais representou uma "instância intermediária" pela qual os processos passam (BARBosa et al., 2011). Por exemplo, um ponto de rede deve prestar contas para a secretaria estadual, que, por sua vez, presta contas para o MinC, enquanto pontos de cultura diretos prestam contas para o MinC.

\section{Avaliações do programa Cultura Viva}

Após aproximadamente oito anos de implantação do programa Cultura Viva, os números refletem crescimento dos convênios, enquanto pesquisas e avaliações realizadas apontam algumas limitações encontradas pelos pontos e pontões de cultura na realização dos convênios (SıIva e Araúso, 2010). Duas pesquisas avaliativas realizadas pelo Instituto de Pesquisa Econômica Aplicada - IPEA (SILva e Araúso, 2010; SıIVA et al, 2011) - como instrumentos de gestão e monitoramento -, além de outros estudos sobre o programa Cultura Viva (Turino, 2009; Silva e Araújo, 2010; SARTOR, 2011; BARBOSA et al., 2011; Silva et al., 2011), indicam baixa capacidade de gestão na execução do programa, problema presente desde a primeira fase do programa e intensificado em sua segunda fase.

Entende-se por baixa capacidade de gestão o despreparo das organizações para lidar com as práticas jurídicas necessárias para a execução de convênios, bem como o reduzido número de técnicos governamentais responsáveis pelo acompanhamento das ações. Em princípio, os pontos e pontões de cultura são incentivos para ações que já existem nas comunidades. Ao submetê-los às regras burocráticas da máquina pública, surgem dificuldades, seja no cumprimento da exigência de estabelecer e seguir um plano de trabalho previamente proposto, ou no atendimento da exigência de adoção de rígidos critérios de prestação de contas, entre outros. As dificuldades decorrem do fato de não haver qualquer contato anterior com esse tipo de procedimento por parte das organizações culturais que se tornam pontos de cultura. 
Vale salientar que os gestores de pontos e pontões de cultura não questionam a necessidade de instrumentos de controle dos recursos e execução dos projetos. O que reforçam é o fato de que a legislação vigente não condiz com a realidade e as práticas dos movimentos culturais (BARBosa et al., 2011, p. 70). A lei de licitações (e contratos da administração pública), como é conhecida a Lei no 8.666/1993, exige que as compras sejam comprovadas por nota fiscal, sendo que, acima de um determinado valor, essas compras devem ser realizadas por meio de licitações, ou, caso a licitação seja dispensada, que haja tomada de preços com pelo menos três "fornecedores". Essas regras, apesar de orientadas para a garantia do bom uso dos recursos públicos, inviabilizam, por exemplo, a aquisição de bonecos que um específico artesão da comunidade faz, por esse não emitir nota fiscal.

Muitas organizações, por desconhecerem a legislação, gastaram os recursos de forma indevida, ou aceitaram recibos em vez de notas fiscais, e, assim, tiveram suas prestações de contas invalidadas. Esses são alguns entre inúmeros exemplos que podem ser usados para demonstrar como a lei de licitações está distante da realidade do público beneficiário do programa Cultura Viva. Trata-se da mesma legislação que serve de base a contratos de grandes obras públicas e relativos à aquisição de bens e serviços de forma geral. Essa dificuldade é apontada pelo idealizador do programa:

A lógica de convênio é uma lógica ultrapassada. A legislação [Lei no 8.666/ 1993] é a mesma para fazer um contrato com uma grande obra de bilhões, como a transposição do Rio São Francisco, e um contrato com um ponto de cultura numa pequena localidade no interior da Bahia que vai receber cinco mil reais com meia dúzia de mestres de terreiro. É a mesma lógica, e não tem cabimento. São objetos diferentes (TuRINo, entrevista concedida às autoras em 22 de janeiro de 2013).

Organizações culturais familiarizadas com procedimentos burocráticos têm menos dificuldades de gestão. São capazes de se manter devido à sua estruturação interna, e reconhecem que organizações com menor estrutura não têm a mesma desenvoltura. Muitas organizações culturais, sobretudo aquelas aprovadas nos primeiros editais, nunca tinham trabalhado com recursos públicos, e tiveram muitas dúvidas sobre seu uso, sendo que a equipe reduzida da SCDC não conseguiu sanar todas as dúvidas a tempo (Sılva e Araújo, 2010). Assim, muitas ações foram realizadas sem a devida orientação, invalidando o uso dos recursos de acordo com o exigido pela Lei $n$ 0 8.666/1993.

Os atrasos no repasse de recursos para os pontos de cultura complexificaram a gestão do programa, uma vez que ações foram realizadas esperando um recurso 
que não foi repassado, gerando juros e dívidas para os pontos e pontões de cultura. Mesmo organizações culturais com maior estrutura, ou seja, com capacidade para continuar suas ações sem os recursos destinados ao ponto de cultura, afirmam que os atrasos são problemáticos.

Entre outros efeitos da baixa capacidade de gestão do programa Cultura Viva, destaca-se ainda a indefinição das competências dos atores governamentais, que se sobrepõem e geram conflito de autoridade e desencontro de informações. Há ainda, associada à baixa capacidade de gestão por parte do setor público, insuficiência dos instrumentos de monitoramento, com ausência de dados sistematizados. A inclusão de Estados e Municípios intensificou a perda de memória sobre o programa, ao favorecer a pulverização das informações. Além disso, o fato de a organização à frente do ponto de cultura ser identificada por vários nomes - razão social, nome fantasia, nome do projeto do ponto de cultura, nome fantasia do ponto de cultura, e assim por diante (SIC, 2012) - acaba gerando, mesmo que não intencionalmente, outras dificuldades para a sistematização das informações.

Os problemas gerenciais tanto das organizações quanto dos gestores estatais, assim como a restrição orçamentária do programa, surgiram desde os primeiros convênios, mas se intensificaram na segunda fase do programa, com a inserção de novos atores, Estados e Municípios. Sobre a gestão compartilhada, o fato de se criar uma instância intermediária faz com que a secretaria estadual ou municipal possa apoiar os pontos de rede de forma mais próxima do que a equipe do MinC poderia fazer, já que amplia o número de gestores responsáveis pelo programa. Ademais, a gestão compartilhada abre espaço para diferentes interpretações de uma mesma norma. Isso faz com que haja informações imprecisas ou, em alguns casos, contraditórias (BARBosa et al., 2011).

Apesar das críticas à gestão compartilhada, o fato é que essa ampliou o número de pontos e pontões de cultura pelo País, sendo a segunda fase do programa responsável pela disseminação do programa Cultura Viva, ao triplicar o número de convênios realizados. Segundo a SCDC, havia 3.703 pontos de cultura até o ano de 2012 (Rollemberg, 2012). Dos 3.703 pontos de cultura, cerca de 70\% eram convênios vigentes em 2012, em diferentes etapas: ajustes, seleção, assistência, prestação de contas, monitoramento, entre outras etapas. A distribuição de pontos e pontões de cultura pelo País revela concentração em São Paulo e Rio de Janeiro, sobretudo quando se trata de pontões não vigentes, mas que continuam realizando ações, ou seja, com convênio encerrado. Por outro lado, a Região Nordeste, com destaque para Ceará e Pernambuco, e a Região Sul apontam grande número de pontões de cultura, sobretudo aqueles 
ainda vigentes em 2012. São Paulo concentra o maior número de pontos e pontões de cultura, com aproximadamente $20 \%$ do total de pontos de cultura do País. Rio de Janeiro, Rio Grande do Sul, Ceará e Bahia também têm destaque em relação ao número de pontos de cultura.

O aumento do número de pontos de cultura e o acúmulo de problemas, ressaltados pelos resultados das avaliações e complementados pela experiência adquirida pelos gestores das três esferas, da sociedade civil e dos parceiros, construíram o cenário que levaria à terceira fase do programa Cultura Viva: seu redesenho.

\section{Terceira fase do programa}

Mesmo que alguns problemas tenham sido identificados desde o início do programa Cultura Viva, e que, durante as duas primeiras fases, ações tenham sido tomadas para amenizar seus efeitos, um movimento maior de redesenho se deu na terceira fase do programa, que buscou amenizar os problemas identificados ao longo das primeiras fases de implementação e ajustar características do programa, processo que aconteceu no momento de conclusão da pesquisa em que se baseia este artigo.

Ao longo do ano de 2011, foram realizados mutirões para solucionar o gargalo de prestações de contas pendentes, tanto pelo MinC quanto pelas redes estaduais, bem como contratação de consultorias para complementar o trabalho dos gestores públicos, e realização de cursos e formações para os gestores de pontos e pontões de cultura (Sılva et al., 2011). Também nesse período foi proposto o Projeto de Lei $(P L)$ no 757/2011. Escrito inicialmente por organizações culturais durante encontros periódicos dos envolvidos no programa Cultura Viva (as Teias), e apresentado pela deputada Jandira Feghali (PCdoB/RJ), em 27 de julho de 2012, foi aprovado na Comissão de Educação e Cultura o PL no 757 de 2011, que instituiu legalmente o Programa Nacional de Cultura, Educação e Cidadania - Cultura Viva, sendo que, em 28 de novembro de 2012, o PL no 757/2011 foi também aprovado (por unanimidade) na Comissão de Finanças e Tributação da Câmara dos Deputados, e em 16/10/2013 foi apresentado ao Senado Nacional, identificado como PL no 90/ 2013. Destaca-se que o programa foi criado institucionalmente por meio de portaria; a lei que o apoia surgiu aproximadamente sete anos depois, já incorporando as revisões derivadas do processo de implementação.

Como resposta aos problemas identificados durante a implementação do programa, esse projeto inclui a proposição de mecanismos que alteram dispositivos da lei de licitações, garantindo maior flexibilidade para as prestações de contas de organizações culturais. A alteração se dá ao inserir ações culturais na 
modalidade de objeto especial. Com isso, alguns itens não serão exigidos com o mesmo rigor aplicado, por exemplo, em obras públicas. Serão considerados casos de ausência de estabelecimentos que emitem nota fiscal, ausência de concorrentes, entre outros fatores que dificultam as prestações de contas de organizações culturais. A medida se baseia no entendimento de que as necessidades de gastos das organizações culturais têm peculiaridades, seja de disponibilidade regional ou da natureza das compras e, portanto, tais gastos podem ser interpretados como objetos especiais.

Um movimento de mudança maior se deu em 2012, com a formação de um grupo de trabalho para o redesenho do programa Cultura Viva (GT Cultura Viva), instaurado pela Portaria no 45 de 19 de abril de 2012. O GT Cultura Viva é coordenado pelo Ipea, sob supervisão do MinC, contando com a participação de representantes de órgãos e entidades envolvidos na política nacional de cultura (BRASIL, 2012). A intenção do GT Cultura Viva é construir uma proposta de redesenho juntamente com as organizações culturais que compõem o programa. Para tanto, foram realizadas reuniões, cujas datas foram divulgadas por meios digitais, e os documentos produzidos e as avaliações que embasam as discussões estão disponibilizados no portal do MinC.

O GT Cultura Viva propõe formação continuada para os gestores de pontos e pontões de cultura, e criação de uma plataforma digital capaz de integrar banco de dados, arquivos e memória institucional, bem como parâmetros para a descentralização do programa (Gt Cultura Viva, 2012). Dessa forma, espera-se amenizar os problemas de capacidade de gestão por meio, justamente, da gestão compartilhada: o fortalecimento das redes, nas quais os próprios pontos e pontões de cultura apoiam-se uns aos outros e ampliam a divulgação e a memória de suas ações, bem como discutem, em conjunto, alternativas para os gargalos encontrados.

Além das modalidades de ponto de cultura, pontão de cultura, ponto de rede e pontinhos, o redesenho propõe a adoção da modalidade de chancela, que reconhece pontos de cultura, instituições e grupos culturais que têm histórico de atuação cultural, sem que convênios sejam firmados. Para tanto, são concedidos prêmios e certificados às organizações culturais chanceladas como pontos de cultura. A prática de concessão de prêmios vem sendo cada vez mais adotada pelo programa Cultura Viva, com destaque para o caso de São Paulo.

Por se tratar de um processo em curso, não é possível afirmar em que medida o redesenho modificará o programa Cultura Viva, e quais serão seus impactos. Por outro lado, o fato de haver um processo de redesenho indica que esforços estão sendo feitos para sanar os problemas identificados durante o processo de 
implementação dessa política pública, demonstrando como a implementação traz elementos para que a formulação previamente feita seja revista e melhorada. Por fim, é possível destacar que o programa Cultura Viva tem se disseminado e se alterado ao longo desses oito anos, o que revela capacidade de responder às dificuldades identificadas no processo de implementação.

\section{Considerações finais}

O objetivo do presente artigo foi demonstrar como o processo de implementação de determinada política pública se modifica e sofre adaptações ao longo do tempo e que, nesse processo, ocorre um redesenho da política. Vale destacar que não se trata de uma demonstração inovadora deste trabalho, pois teorias sobre análise de políticas públicas há tempos se debruçam sobre o tema. Trata-se da apresentação de um caso empírico de como o processo de implementação redefine a política pública, o que converge com algumas das abordagens de implementação aqui apresentadas, em especial a concepção do processo de implementação que reconhece o convívio de elementos das abordagens "de cima para baixo" e "de baixo para cima". O caso do programa Cultura Viva, nesse sentido, é emblemático de como um processo de implementação, mesmo que simplificado, pode alterar ou, no mínimo, questionar os critérios estabelecidos no processo de formulação.

Pelos dados apresentados, foi possível constatar que o processo de implementação é caracterizado por gargalos e potencialidades que podem - e devem - ser tratados para possibilitar a continuidade de uma política pública, ou mesmo para apoiar a opção por sua extinção. Ao longo da implementação, no caso estudado, foi possível identificar um processo de revisão constante dos objetivos, critérios e instrumentos de gestão previamente formulados, implicando, inclusive e especialmente, críticas e alterações nas regras de conveniamento de organizações culturais. Enquanto a primeira fase de implementação do programa seguiu o escopo do programa tal qual previamente estabelecido, as limitações identificadas levaram à inclusão de outros entes federados, ampliando assim os recursos disponíveis e o número de organizações conveniadas, bem como complexificaram os processos e ampliaram as instâncias responsáveis pelo programa. O desenvolvimento dos convênios firmados trouxe à tona problemas estruturais, seja com as regras de financiamento e instrumentos de gestão existentes, seja com a falta de familiaridade das organizações para com tais regras e instrumentos, culminando na necessidade de redesenho do programa. Vale ressaltar ainda que, mesmo sem garantia da continuidade do programa, muitas 
organizações culturais com convênios encerrados permanecem realizando as ações e se identificando enquanto pontos de cultura, apontando para um enraizamento das noções de protagonismo e rede.

A implementação do programa Cultura Viva é composta por diferentes "fases" que, apesar de apresentadas aqui linearmente, se sobrepõem ao longo da existência do programa. As adaptações mais perceptíveis são decorrentes de decisões de gestão, durante o que se definiu aqui como a segunda fase do programa, e de adaptações que se fazem necessárias para que as organizações culturais continuem a atuar dentro da legalidade, processo que caracteriza, sobretudo, a terceira fase do programa.

Finalmente, cabe ainda destacar o fato de a implementação do programa Cultura Viva ocorrer tendo como um de seus elementos centrais a participação de agentes não governamentais. Assim, são atores não governamentais que participam da "redefinição" da própria política na fase de implementação. Como tem sido destacado pela literatura sobre políticas públicas no Brasil, a participação de atores não governamentais é um dos elementos centrais da redefinição das políticas públicas após a redemocratização do País, em todas as etapas do processo.

\section{Referências bibliográficas}

Barbosa, Cláudia L; Medeiros, Rosana C. F.; Lyra, Valéria M. G. Avaliação dos Pontões de Cultura do Programa Cultura Viva: o perfil dos Pontões de Cultura. O Olhar dos gestores do Programa Cultura Viva. Relatório da Pesquisa Avaliativa do Programa Cultura Viva. IPEA: Brasília, 2011.

BARDACH, Eugene. The implementation game: What happens after a bill becomes a law. v. 1. Cambridge, MA: Mit Press, 1977. p. 323.

A practical guide for policy analysis: the eightfold path to more effective problem solving. 3 ed. Washington: CQ Press, 2009, p. 144.

BRASIL. Ministério da Cultura. Institui Grupo de Trabalho, denominado GT - Cultura Viva, para elaborar proposta de redesenho do Programa Cultura Viva. Portaria no 45, de 19 de abril de 2012.

Calabre, Lia. Políticas culturais no Brasil: dos anos 1930 ao século XXI. Rio de Janeiro: Editora FGV, 2009.

FARAH, Marta Ferreira Santos. Teoria de políticas públicas. In: Loureiro, Maria Rita e Abrucio, Fernando (org.). Políticas públicas e o desenvolvimento brasileiro. Rio de Janeiro: Editora FGV (no prelo).

FreY, Klaus. Políticas públicas: um debate conceitual e reflexões referentes à prática da análise de políticas públicas no Brasil. Planejamento e políticas públicas, n. 21, p. 211-259, jun. 2000. 
Fuks, Mario. Definição da agenda, debate público e problemas sociais: uma perspectiva argumentativa da dinâmica do conflito social. Bib, n. 49, p. 79-94 10 sem. 2000.

Gt Cultura Viva. Relatório do Redesenho do Programa Cultura Viva. Grupo de Trabalho Cultura Viva. IPEA/SCDC: Brasília, nov. 2012.

HiLl, Michael. Implementação: uma visão geral. In: Saravia, Enrique e Ferrarezı, Elisabete (Orgs). Políticas Públicas: coletânea, v. 1. Brasília: ENAP, 2006, p. 61-89. KINGDon, John. Agendas, alternatives, and public policies. 3ed. Nova York: Harper Collins, 2003 (1984).

Majone, Giandomenico and Wildavsky, Aaron. Implementation as evolution. In: Theodoulou, Stella Z. and Cahn, Matthew A (Orgs). Public policy: the essential readings. New Jersey: Prentice Hall, Upper Saddle River, 1995. p. 140-153.

Mınc, Ministério da Cultura. Programa Arte Cultura e Cidadania - Cultura Viva. Disponível em: <http://www.cultura.gov.br/culturaviva/cultura-viva/> Último acesso em março de 2013.

ReINACH, S. Gestão transversal das políticas públicas no âmbito federal brasileiro: uma leitura inicial. 2013. 163 f. Dissertação (Mestrado) - Escola de Administração de Empresas de São Paulo. São Paulo.

Rollemberg, Márcia. Apresentação da equipe da Secretaria de Cidadania e Diversidade Cultural. Secretaria de Cidadania Cultural. Brasília, 2012.

SARTOR, Carla D. As Políticas públicas culturais e a perspectiva da transformação: a experiência coletiva nos Pontos de Cultura. 2011. 404 p. Tese (Doutorado em Serviço Social) - Departamento de Serviço Social, Pontifícia Universidade Católica do Rio de Janeiro, 2011.

Sıc, Sistema de Informação da Cultura. Lei de Acesso à Informação. Brasília: MinC, 2012. Sılva, Frederico A. Barbosa da; ARAúso, Herton Ellery. Cultura viva: Avaliação do Programa Arte Educação e Cidadania. Brasília: IPEA, 2010. p. 148.

SILvA, Frederico et al. Cultura viva: as práticas de pontos e pontões. 1. ed. Brasília: IPEA, 2011. p. 261.

Silva, P. L. B.; Melo, M. A. B. de. O processo de implementação de políticas públicas no Brasil: características e determinantes de avaliação de programas e projetos. Cadernos de Pesquisa, no 48, NEPP, Unicamp, Campinas, 2000, p. 17.

SubIRATS, Joan et al. Análisis y gestión de políticas públicas. 2. Ed. Barcelona: Editorial Planeta, 2012. p. 285.

Turino, Célio. Formulador do programa Cultura Viva e Secretário de Cidadania Cultural do Ministério da Cultura entre 2004 e 2010. Entrevista concedida aos autores em 22/01/2013, em São Paulo.

Ponto de Cultura: O Brasil de Baixo para Cima. São Paulo: Editora Anita Garibaldi, 2009. p. 246. 
WinTeR, Søren C. Perspectivas de implementação: status e reconsideração. In: Peters, B. G. \& PIERRE, J (Orgs). Administração pública: coletânea. São Paulo: Editora UneSP; Brasília, DF: ENAP, 2010. p. 649.

Anny Karine de Medeiros

Mestre em Administração Pública e Governo pela Fundação Getúlio Vargas - SP (2013) e pesquisadora da Rede Amigos da Amazônia e do Centro de Estudos em Administração Pública e Governo. Contato: annykmedeiros@gmail.com

Marta Ferreira Santos Farah

Doutora em Administração Pública e Governo da Fundação Getúlio Vargas - SP (1992) e professora da Escola de Administração de Empresas da Fundação Getúlio Vargas. Contato: marta.farah@fgv.br 
